\title{
"Namorar é só sofrência": violências na relação afetivo-sexual de adolescentes de uma escola na região Costa Verde, Rio de Janeiro, Brasil
}

\author{
"Dating is pure suffering": violence within affective-sexual \\ relationships between adolescents in a school in the Costa Verde, \\ Rio de Janeiro, Brazil
}

Renata de Souza Carvalhaes (https://orcid.org/0000-0002-2592-8484) ${ }^{1}$

Claudia Mercedes Mora Cárdenas (http://orcid.org/0000-0003-4854-3429) ${ }^{1}$
${ }^{1}$ Instituto de Medicina Social, Universidade do Estado do Rio de Janeiro. R. São Francisco Xavier 524, Maracanã. 20550-013 Rio de Janeiro RJ Brasil. rcarvalhaes@gmail.com

\begin{abstract}
This work is the result of a master's thesis that aimed to understand students' perceptions of violence within affective-sexual relationships between adolescents in a public school in the Costa Verde, Rio de Janeiro. The study corpus was derived from participant observation in the school and in-depth interviews with three girls and three boys aged between 18 and 24 years. The core areas of analysis were affective-sexual trajectories, experiences involving violence within relationships, and agency in the face of conflict. The findings reveal that violence is part of the everyday lives of adolescents and reinforce the victim/aggressor dichotomy. The adolescents' interpretations of violence were divided into two categories: "suffering" and "serious acts of violen$c e$ ". These understandings influence the recognition of violence and agency. The reproduction of gender norms contributes to sustaining gender hierarchy and inequalities, which affect girls and boys differently. Silence on this issue contributes to the invisibility of violence within relationships and the consequent failure to seek support from relevant organizations and services. Further research is needed to gain a deeper understanding of violence within affective-sexual relationships between adolescents.

Key words Adolescence, Dating, Violence
\end{abstract}

Resumo O presente trabalho é resultado de uma pesquisa de mestrado que objetivou compreender como as violências nas relações afetivo-sexuais na adolescência são significadas por estudantes de uma escola estadual da região Costa Verde do Rio de Janeiro. O corpus da pesquisa deriva da observação participante no espaço escolar e de entrevistas em profundidade com 3 moças e 3 rapazes entre 18 e 24 anos. Os eixos de análise foram: as trajetórias afetivo-sexuais, as experiências que envolvem algum tipo de ação violenta no relacionamento e as agências diante dos conflitos. Os resultados revelam que as violências fazem parte do cotidiano e reforçam a dicotomia vítima e agressor. As interpretações da violência são divididas em dois sistemas, a "sofrência" e "ações violentas graves", essas compreensões interferem no reconhecimento da violência e em suas agências. A reprodução de padrões sociais de gênero contribui para a manutenção de hierarquias e desigualdades que atingem a moças e rapazes de diferentes formas. $O$ silenciamento a respeito do tema contribui para a invisibilidade da violência no relacionamento $e$ consequentemente a não procura de cuidado junto aos serviços de saúde. É posto como desafio a expansão de estudos que possibilitem compreender melhor a violência nas relações afetivo-sexuais de adolescentes.

Palavras-chave Adolescência, Namoro, Violência 


\section{Introdução}

O tema da violência na adolescência é geralmente associado às violências praticadas por sujeitos adolescentes, tais quais: violências de gangues, nas escolas e nas ruas ${ }^{1}$, ou às violências em que eles são alvo por parte dos adultos. Entretanto, as violências ocorridas no relacionamento afetivo-sexual entre adolescentes dificilmente são discutidas.

Os primeiros estudos sobre o tema surgiram na década de 1980 no Canadá e nos Estados Unidos. Com o tempo, a temática ganhou espaço em Portugal, México, Espanha, Brasil, entre outros países.

No Brasil, os trabalhos vêm crescendo a partir da última década ${ }^{2-4}$. Algumas pesquisas privilegiam abordagens epidemiológicas com o intuito de quantificar prevalências e categorizar as ações tidas como violentas ${ }^{5-7}$.

Caridade e Machado ${ }^{5}$ destacam três pontos frágeis para pesquisar as relações violentas no namoro entre adolescentes: a definição de violência; a dificuldade de acessar a população jovem e a escassa produção acadêmica sobre o tema.

A violência no namoro é definida como atos, omissões e atitudes que produzam ou tenham potencial de gerar dano emocional, físico e sexual à parceira ou ao parceiro afetivo-sexual na ausência de vínculo marital ${ }^{7}$. Embora a violência pareça ser mais expressiva no namoro, ela também é verificada em relações como o "ficar" (relação despertada por atração ou interesse que resulta na troca de carícias e beijos, podendo haver, ou não, relações sexuais).

Um ponto importante na discussão sobre violência no namoro entre adolescentes é a aparente igualdade da violência perpetrada por rapazes e moças $^{2,5,8}$. Esses dados estimulam as discussões em torno da dicotomia mulher/vítima e homem/ agressor e às diferentes manifestações das violências conforme o gênero. Esse cenário contempla as violências vividas pelos rapazes ainda pouco exploradas nas pesquisas e evidencia que moças e mulheres, de certa forma, também são agentes nas cenas de violência.

O presente artigo é resultado de uma pesquisa de mestrado em Saúde Coletiva intitulada "Entre laços e nós: narrativas de violência nas relações afetivo-sexuais de adolescentes de uma escola na região Costa Verde (RJ)". Esta foi desenvolvida pela primeira autora, sob orientação da segunda autora.

A ideia da pesquisa surgiu da prática profissional da primeira autora, enquanto psicóloga em uma Secretaria Municipal de Educação. Nos aten- dimentos, os adolescentes narravam situações que podiam ser classificadas como violência no namoro, mas que, na maioria das vezes, não ganhavam essa interpretação. Esse fato trouxe algumas questões: O que fazia com que essas situações ganhassem diferentes significados? Quais aspectos das normas de gênero e sexualidade podiam influenciar as ações violentas nos relacionamentos? Quais as agências realizadas frente à violência nas relações afetivo-sexuais?

É necessário ir além das categorias fixas e dos conceitos preestabelecidos da violência e das definições a priori da adolescência e sexualidade como um "problema social"". Concebemos a adolescência e a juventude a partir de uma perspectiva cultural e contextual acerca do ciclo de vida. Enquanto construções sociais, estas experiências são analisadas na sua multiplicidade e heterogeneidade.

A definição normativa no Brasil sobre a adolescência e da juventude é atravessada por distintas delimitações cronológicas que se justapõem em alguns períodos, como, por exemplo: o Estatuto da Criança e Adolescente ${ }^{10}$ (ECA), que define a fase dos 12 aos 17 anos, 11 meses e 29 dias de idade; já a Organização Mundial de Saúde considera a adolescência o segmento entre 10 e 19 anos, 11 meses e 29 dias de idade e a juventude como o período entre 15 e 24 anos; e, por fim, no Estatuto da Juventude ${ }^{11}$, jovens são os sujeitos entre 15 e 29 anos de idade.

Optamos por utilizar o termo adolescência, pois era a forma como os interlocutores se definiam (indistintamente da idade cronológica); trabalhamos com trajetórias de vida deste período devido à necessidade de dialogar com o campo de garantia de direitos de adolescentes, o ECA, e da saúde. O uso da nomenclatura adolescente abarca também jovens com mais de 18 anos.

Considerando os aspectos acima expostos, o objetivo da pesquisa foi analisar como a violência nas trajetórias afetivo-sexuais ao decorrer da adolescência é interpretada por estudantes de uma escola estadual no Rio de Janeiro.

\section{Metodologia}

Consideramos a escola um local privilegiado para acessar o adolescente, seus espaços de socialização e sociabilidade. A pesquisa ocorreu na região Costa Verde do Rio de Janeiro, em uma escola estadual de ensino fundamental II ( $6^{\circ}$ a $9^{\circ}$ ano) e médio (regular e com cursos profissionalizantes), localizada na região central da cidade. 
Mesmo a pesquisadora sendo profissional de uma Secretaria Municipal de Educação, optamos por realizar a pesquisa em uma escola estadual no intuito de se posicionar em campo como pesquisadora, evitando a assim a sobreposição de papéis.

Dentre os 1.695 alunos matriculados em 2018, havia estudantes brancos, pardos e negros, de várias idades, classes sociais e residentes em diversos bairros da cidade e municípios vizinhos. Esse quadro proporcionou a possibilidade de interação de alunos com diferentes realidades culturais e sociais.

A metodologia utilizada é de cunho etnográfico $^{12}$, cujo material empírico resultou da observação participante realizada ao longo de sete meses (março-outubro/2018), no pátio escolar. Também foram realizadas 6 entrevistas (3 moças e 3 rapazes) em profundidade. Ao decorrer do artigo algumas situações serão exemplificadas com narrativas de alguns entrevistados e interlocuções ocorridas no pátio.

A entrada no campo foi gradual: inicialmente a pesquisadora era associada à equipe escolar, $\mathrm{o}$ que dificultava criar vínculos com os estudantes, no entanto, as funcionárias do portão estavam sempre conversando com os adolescentes. Elas foram o elo inicial para estabelecer contatos com os estudantes. Mas, para evitar ser associada à "tia do portão" e conseguir instituir a figura de pesquisadora no espaço, foi retomada a circulação no pátio e, assim, ampliou-se a rede de contatos.

A observação participante focou nas dinâmicas do ambiente escolar; nas relações entre estudantes e os profissionais; nas representações e expressões corporais; nos comportamentos pautados no gênero e sexualidade e nos relatos de violências nos relacionamentos afetivo-sexuais.

Foram convidados para as entrevistas uma moça e um rapaz de cada modalidade do ensino médio, que tiveram contato prévio com a pesquisadora através da convivência no pátio. Foram consideradas as seguintes características sociais dos entrevistados: idades entre 18 e 24 anos, com diferentes raças/cor e sem distinção de orientação sexual (identificação com base nos relatos das práticas sexuais).

A opção por essa faixa etária teve por intuito garantir o caráter retrospectivo das entrevistas e respeitar a autonomia dos jovens na participação, conforme Resolução 466/2012 do Conselho Nacional de Saúde ${ }^{13}$. O projeto foi aprovado pelo Comitê de Ética em Pesquisa. Os adolescentes entrevistados foram orientados e esclarecidos sobre os riscos e benefícios da pesquisa e sobre o sigilo de suas identidades por meio da utilização de nomes fictícios. O sigilo e os cuidados éticos se estendem para os relatos utilizados a partir da interação no pátio via a observação participante.

O roteiro de entrevista não lançou mão do termo violência, com exceção de seu final, em que foi questionado se, a partir das experiências afetivas e das histórias narradas, eles haviam vivenciado violência ou "relacionamento abusivo". A indagação sobre "relacionamento abusivo" foi inserida após percebermos o uso dessa expressão durante o trabalho de campo. Em suma, a interlocução visou compreender os significados atribuídos aos termos violência e relacionamento abusivo.

Cabe dizer que o uso da expressão "relacionamento abusivo"14 se intensifica no Brasil a partir de 2014, ele tem sido utilizado como sinônimo de violência física e/ou emocional. A partir de coletivos feministas e instituições que lidam com assuntos referentes à violência contra a mulher, a expressão ganhou voz na internet e fora dela.

As entrevistas abordaram os seguintes aspectos: trajetória afetivo-sexual desde as experiências iniciais; vivências que envolveram algum tipo de ação violenta no relacionamento e as agências diante dos conflitos. O Quadro 1 trata das características sociodemográficas dos entrevistados e o Quadro 2 sintetiza as narrativas dos entrevistados.

A análise partiu do conceito de gênero de Butler ${ }^{15}$ e suas intersecções com classe, raça e sexualidade. Lançamos mão da noção de "roteiros sexuais" de Gagnon ${ }^{16}$, bem como da perspectiva da "violência relacional" de Gregori ${ }^{17}$, que entende mulheres e homens como autores e receptores de violência. E, para compreender as agências que os sujeitos fazem diante dos conflitos e violências, alinhamo-nos ao olhar de Ortner ${ }^{18}$.

\section{Resultados}

\section{Afetos, sociabilidade e espaço escolar}

A sexualidade é tecida a partir de experimentações, troca de afeto, desejo e busca por prazeres. Essas aprendizagens são influenciadas pelos roteiros sexuais ${ }^{16}$, que são habilidades interativas aprendidas nos contextos sociais e interiorizadas por meio de regras e valores sociais, por meio da convivência familiar, com amigos, escolar, religiosa, com o que mídia ${ }^{19,20}$ reproduz e, atualmente, com forte influência da convivência virtual nas redes sociais ${ }^{21,22}$.

Os roteiros tendem organizar os pensamentos e comportamentos sexuais e as escolhas das parcerias. Alguns valores e expectativas que permeiam 
Quadro 1. Caracterização sociodemográfica dos adolescentes entrevistados.

\begin{tabular}{|c|c|c|c|c|c|}
\hline $\begin{array}{l}\text { Nome/ } \\
\text { Idade }\end{array}$ & $\begin{array}{c}\text { Raça/cor } \\
\text { autodeclarada }\end{array}$ & Escolaridade & Renda Familiar & Religião & $\begin{array}{c}\text { Composição } \\
\text { Familiar }\end{array}$ \\
\hline $\begin{array}{l}\text { Ana } \\
20 \text { anos }\end{array}$ & Negra & $2^{\circ}$ ano E.M ${ }^{\star}$ & $0-1 \mathrm{~S} . \mathrm{M}^{\star \star}$ & Evangélica & $\begin{array}{l}\text { Pai, madrasta, } 3 \\
\text { irmãos }\end{array}$ \\
\hline $\begin{array}{l}\text { Ingrid } \\
19 \text { anos }\end{array}$ & Branca & $3^{\circ}$ ano E.M & Não informado & \begin{tabular}{|l}
$\begin{array}{l}\text { Evangélica } \\
\text { (não praticante) }\end{array}$ \\
\end{tabular} & $\begin{array}{l}\text { Mãe, padrasto e } \\
1 \text { irmã }\end{array}$ \\
\hline $\begin{array}{l}\text { Lígia } \\
18 \text { anos }\end{array}$ & Branca & $1^{\circ}$ ano E.M & Não informado & $\begin{array}{l}\text { Espírita } \\
\text { (não praticante) }\end{array}$ & $\begin{array}{l}\text { Pai, madrasta e } 1 \\
\text { irmã }\end{array}$ \\
\hline $\begin{array}{l}\text { Carlos } \\
19 \text { anos }\end{array}$ & Pardo & $3^{\circ}$ ano E.M & 3-5 S.M & $\begin{array}{l}\text { Não possui } \\
\text { (Pais evangélicos) }\end{array}$ & Pai, mãe, 1 irmã \\
\hline $\begin{array}{l}\text { Guilherme } \\
18 \text { anos }\end{array}$ & Negro & $1^{\circ}$ ano E.M & 1-3 S.M & $\begin{array}{l}\text { Católico } \\
\text { (não praticante) }\end{array}$ & Pai, mãe, 1 irmão \\
\hline $\begin{array}{l}\text { Willian } \\
18 \text { anos }\end{array}$ & Negro & $3^{\circ}$ ano E.M & 3-5 S.M & Evangélico & $\begin{array}{l}\text { Pai, mãe, } 2 \\
\text { irmãos }\end{array}$ \\
\hline
\end{tabular}

*E.M: Ensino Médio; ${ }^{\star \star S . M: ~ S a l a ́ r i o ~ M i ́ n i m o . ~}$

Fonte: Elaborado pelos autores.

Quadro 2. Experiências afetivo-sexuais; vivência de violências, rede de apoio.

\begin{tabular}{|c|c|c|c|}
\hline Nome & Experiência afetivo-sexual & Violência praticada ou sofrida & Agência \\
\hline Ana & $\begin{array}{l}\text { Primeiro beijo: } 14 \text { anos. } \\
\text { Status de relacionamento: } \\
\text { solteira. }\end{array}$ & $\begin{array}{l}\text { Sofreu e revidou agressão física; } \\
\text { Sofria Violência psicológica; } \\
\text { Foi Induzida a afastar-se dos amigos. }\end{array}$ & $\begin{array}{l}\text { Não buscou ajuda, porém teve } \\
\text { suporte familiar e de amigos; } \\
\text { Não buscou auxílio profissional } \\
\end{array}$ \\
\hline Ingrid & $\begin{array}{l}\text { Primeiro beijo: Não soube } \\
\text { precisar a idade. } \\
\text { Status de relacionamento: } \\
\text { namorava há } 1 \text { ano. } \\
\end{array}$ & $\begin{array}{l}\text { Agressão física, xingamentos, por } \\
\text { ambos; } \\
\text { Controle de celular; } \\
\text { Sofreu Coerção sexual. } \\
\end{array}$ & $\begin{array}{l}\text { Reagia aos conflitos (verbal e } \\
\text { fisicamente). } \\
\text { Não buscou auxílio } \\
\text { profissional. }\end{array}$ \\
\hline Lígia & $\begin{array}{l}\text { Primeiro beijo: } 14 \text { anos. } \\
\text { Status de relacionamento: } \\
\text { solteira. }\end{array}$ & $\begin{array}{l}\text { Agrediu fisicamente um namorado; } \\
\text { Sofreu Coerção sexual; } \\
\text { Havia muitas discussões. }\end{array}$ & $\begin{array}{l}\text { Solicitou apoio da irmã e } \\
\text { amigos. } \\
\text { Recorreu à ajuda psicológica }\end{array}$ \\
\hline Carlos & $\begin{array}{l}\text { Primeiro beijo: } 10 \text { anos. } \\
\text { Status de relacionamento: } \\
\text { namorava há } 2 \text { anos. }\end{array}$ & Não relatou violências. & Recorreu a um amigo. \\
\hline Guilherme & $\begin{array}{l}\text { Primeiro beijo: } 12 \text { anos. } \\
\text { Status de relacionamento: } \\
\text { solteiro. }\end{array}$ & $\begin{array}{l}\text { Discussões e ofensas por ambas as } \\
\text { partes; } \\
\text { Sofreu agressões físicas; } \\
\text { Teve fotos íntimas expostas. }\end{array}$ & $\begin{array}{l}\text { Recorreu à família e às amigas } \\
\text { para solicitar conselhos; } \\
\text { Não buscou auxílio } \\
\text { profissional. }\end{array}$ \\
\hline William & $\begin{array}{l}\text { Primeiro beijo aos } 8 \text { anos. } \\
\text { Status de relacionamento: } \\
\text { solteiro. }\end{array}$ & $\begin{array}{l}\text { Forçou uma namorada a lhe dar um } \\
\text { beijo; } \\
\text { Brigas e insultos por parte da } \\
\text { namorada; } \\
\text { Foi induzido a afastar-se das amigas. }\end{array}$ & $\begin{array}{l}\text { Recorreu ao pai e aos amigos. } \\
\text { Não buscou auxílio } \\
\text { profissional. }\end{array}$ \\
\hline
\end{tabular}

Fonte: Elaborado pelos autores.

os roteiros, influenciados permanentemente pelo contexto e as relações dos sujeitos, tanto podem instigar conflitos e ações violentas, quanto impulsionar agências diante das violências.

A escola representa para alguns o principal lugar para paquerar e encontrar parceiros. Estu- dantes utilizavam o espaço para potencializar seu capital de produção do desejo, sendo o uso do uniforme um exemplo disto. De uso obrigatório, os estudantes o readaptavam e incorporavam ao uniforme elementos advindos dos seus espaços de convivências e da cultura fora da escola. 
O namoro era frequente na escola, havia casais heterossexuais e, em menor frequência, homossexuais. Contudo, as manifestações públicas de afeto eram diferentes, as interações homoafetivas eram mais comedidas quando comparadas às dos casais heterossexuais. Não se viam casais de meninos andando pela escola, apenas de meninas. Embora haja algumas observações a respeito, as observações das interações homoafetivas e discriminações foram limitadas no ambiente investigado.

Comumente as pautas das conversas eram sobre relacionamentos afetivos e geralmente as histórias que surgiam eram em torno das desilusões: "Cada coisa que a gente passa, namorar é só sofrência” (Guilherme, 18 anos). A "sofrência” era uma forma de expressar os acontecimentos negativos na relação, os desentendimentos, ciúmes, traição, términos, as brigas.

Embora a "sofrência" não represente apenas situações de violências, neste artigo o termo é utilizado de maneira sistemática para dividir formas de interpretar as diferentes violências. Dividiremos as relações violentas em dois sistemas, o que chamaremos de "sofrência" e o das "ações violentas graves".

$\mathrm{Na}$ "sofrência”, o lugar de vítima ou agressor é ambíguo. As relações transitam entre a jocosidade, a dor, a humilhação, as práticas violentas não recebem "rótulos". Já no sistema das "ações violentas graves", o lugar da vítima e do agressor são bem definidos, tanto quanto as características das violências e a gravidade das mesmas.

Os distintos valores morais impostos para meninas e meninos eram presentes nas falas dos estudantes e dos profissionais. Na escola, a fama negativa circulava rápida e se tornava assunto de fofoca. As fofocas podem exercer a função de controle social da sexualidade e, em muitos casos, têm um caráter depreciativo das pessoas envolvidas $^{23}$. As consequências mais danosas em decorrência do comportamento sexual recaíam principalmente para as moças heterossexuais, bem como para moças e rapazes com práticas homoafetivas.

As meninas estigmatizadas, carregavam marcas sobre seu status moral ${ }^{24}$ e elas podiam ser penalizadas através de insultos, passavam a ser excluídas dos grupos de amigos e até mesmo agredidas. Entretanto, os garotos geralmente não eram criticados por suas interações afetivo-sexuais, recebiam status de "poderosos" o que reforçava o imaginário de homem viril.

Os estereótipos de gênero são atravessados por moralidades que permeiam e validam a vio- lência. As fofocas e discursos, por exemplo, ilustram como estes estereótipos se reproduzem. De acordo com $\operatorname{Butler}^{15}$ (p.30): “os limites da análise discursiva do gênero pressupõem e definem por antecipação as possibilidades das configurações imagináveis e realizáveis do gênero na cultura”. No entanto, isto não significa que não possa haver outras possibilidades de gênero, mas esses limites são estabelecidos em uma linguagem cultural hegemônica pautada em estruturas binárias que se apresentam como universais.

Quanto às relações homoafetiva, não houve interações com rapazes que se autodeclarassem homossexuais. Quanto às moças, Lígia (18 anos, branca) auxiliou a elucidar algumas situações lesbofóbicas dentro da escola, como por exemplo: "Esse ano eu quase apanhei de uns cinco meninos daqui da escola, eles pegaram uma madeira pra me bater, tipo, porque eu gosto de menina”. Por não confiar na escola, ela não levou o caso à direção. Ela apontou ainda que os funcionários, ao verem casais namorando, davam advertências aos casais homossexuais com mais frequência do que aos casais heterossexuais.

A escola acaba operando como um local de controle, reprodução de moralidades e julgamentos da sexualidade. Desta forma, segundo Louro ${ }^{25}$, torna-se um dos espaços mais complicados para assumir a homossexualidade, por ser um lugar que habitualmente silencia, nega e ignora essas orientações sexuais e, quando estas são "aceitas”, espera-se que sejam vividas de forma discreta.

Essas situações evidenciam a fragilidade da escola em exercer seu papel protetor e de realizar uma reflexão crítica sobre temas de relevância social junto aos estudantes. A rigidez e o pouco diálogo relativos a questões da sexualidade e de gênero geram perda de credibilidade e suscitam o afastamento dos adolescentes nos momentos em que poderiam solicitar apoio da escola.

\section{A violência nas interações afetivo-sexuais}

Nas primeiras semanas no campo, no pátio, Aline (18 anos, branca) narrou que aos 13 anos namorava um rapaz de 18 anos que a pressionava para ter relações sexuais: "Eu era muito nova, não tinha idade pra isso, aí ele ficava cercando um monte de "mulézinha". Ela engravidou aos 14 anos e, em uma briga com o namorado, ele a atingiu com um chute na barriga, o que lhe provocou um aborto: "Ele teve é sorte que eu não dei queixa dele na polícia, se quando eu abortei eu tivesse dado, ele tinha ido preso, ainda mais com a idade que eu tinha, ele era maior". 
O caso ilustra a forma como adolescentes podem estar suscetíveis a violências desde muito cedo e sua fragilidade em buscar ajuda ou a falta de ação da família em recorrer aos órgãos legais a fim de responsabilizar quem comete agressão.

Nos relatos dos adolescentes os principais motivadores dos conflitos foram: ciúme, desconfiança e traição. O ciúme apareceu como um sentimento unânime dos interlocutores da pesquisa. Cabe ponderar que as emoções não são sentimentos universais, são traçadas e legitimadas por "regras de relacionamento", em que há expectativas de reciprocidade e exclusividade ${ }^{26}$. A forma de lidar com o ciúme pode ficar na esfera do sentimento ou ser traduzida em ações, desencadeando brigas com parceiros e terceiros, agressões e etc.

Geralmente os adolescentes justificavam o ciúme através do medo da perda, de traição, insegurança, como demonstra a fala: "Mesmo você 'ficando' com a pessoa, sempre acaba rolando um ciúme. Você acaba ficando insegura, sei lá, ainda mais quando a pessoa acaba tendo também muita amizade com mulher" (Ingrid, 19 anos).

A amizade era um fator forte para gerar ciúmes. Algumas moças relataram situações em que foram levadas a se afastar dos pares, fosse pelo convívio pessoal ou das redes sociais na internet. Quanto aos rapazes, apenas um apontou ser pressionado para se afastar das amigas, mesmo ele as evitando, não cortou vínculos. Esse comportamento controlador tende a cercear principalmente as meninas e mulheres de suas redes de sociabilização8.

Outro aspecto identificado na análise foi o abuso digital, que se destacou pelo controle do celular do parceiro e relato de divulgação de fotos íntimas. Estes comportamentos fazem parte do cotidiano dos adolescentes, sendo motivados pelo ciúme e pela desconfiança. Estes achados convergem com a literatura, que aponta a dificuldade dos adolescentes de significar os abusos digitais como violência ou, quando a situação é incômoda, tendem a qualificá-la como comportamento "irritante" e esse tipo de abuso é comumente interpretado como "prova de amor", sensação de segurança, cuidado ou ainda como uma "brincadeira"27.

Quanto à exposição de fotos, foram narrados dois casos: um de uma moça e outro de um rapaz. Em ambas as situações, as imagens foram exibidas pessoalmente aos colegas e as consequências deixam claras as hierarquias de gênero em torno da sexualidade. À medida que nenhum comentário foi feito ao menino, a menina recebeu uma série de provocações que ocasionaram briga e transferência de unidade escolar.

Como assinalado por Petrossillo ${ }^{22}$, a exibição do rapaz através das fotos é uma forma de mostrar sua virilidade, já o ato da moça é visto como "putaria", ou seja, comportamentos sexuais inadequados. Essas exposições evidenciam os valores morais em torno da sexualidade feminina, sendo as mulheres as mais atingidas pelo abuso digital ${ }^{8}$.

A coerção sexual foi mencionada por duas moças que relataram serem pressionadas para terem relações sexuais. Ambas consideravam a situação como experiências ruins e reclamavam por não serem respeitadas.

As agressões físicas pareciam ser comuns no cotidiano, foram citados episódios ocorridos no próprio relacionamento e nos de amigos. Como demonstram as narrativas: "Ter falado merda, ter xingado de piranha, eu tomava tapa na cara. Eu era mais novo e era idiota mesmo" (Guilherme, 18 anos, negro). "Um garoto que eu tava ficando, falou uma graça pra mim, que eu não lembro o que era, e me deu o tapa. [...] eu virei a mão de volta. Aí nisso que ele veio pra cima de mim, eu fui pra cima dele" (Ana, 20 anos, negra).

Os garotos não citaram descobertas de traição diferente das moças, as quais tiveram distintas reações como a indignação, a depressão seguida de autoagressão e a agressão física ao parceiro. Segue um relato de campo ilustrativo: em uma conversa no pátio, Débora (14 anos, negra) relatou sobre a traição do namorado, ela acometida pela raiva o agrediu fisicamente. Ele a segurou pelos braços, para contê-la, deixando-os roxos. Ela mencionou que não sabia como o namorado não "foi para cima", em seguida, acrescenta: "se viesse, eu chamava a polícia". Débora, ao ser questionada sobre a possibilidade do namorado chamar a polícia para ela, afirma: "ele não poderia fazer isso, mas eu chamava e metia Maria da Penha". Ela alegava que ele não poderia bater nela, pois ela era mulher, então foi interrogada se menina pode bater em menino, sem reação, respondeu: "Eu bato mesmo, tava com raiva".

A partir das situações narradas, notam-se ambiguidades e tensões nas relações de gênero, a dicotomia vítima e agressor é reforçada e as agressões violentas são naturalizadas no cotidiano. Para Gregori ${ }^{17}$, os diferentes padrões instituídos para homens e mulheres, por não serem lineares e fixos, são atualizados nas relações interpessoais e podem constituir uma dinâmica de comunicação violenta entre o casal.

A diferença de idade apresentou-se como relevante na escolha de parceiros. Os rapazes 
chamavam a atenção dos amigos que "ficavam" com meninas "novinhas", pois podia "dar cadeia" (menção indireta a Lei de Estupro de Vulnerável $^{28}$ ), e não viam problemas dos meninos se relacionarem com mulheres mais velhas: "[...] o cara de 18 nunca vai estar com a menina de 14 só pra dar uns beijinhos, ele sempre vai querer coisa a mais [...], a menina de 18 , ela também vai querer fazer, só que a mulher quer mais um relacionamento sério, quer afeto. Homem tá nem aí" (Juan, 14 anos).

Novamente os estereótipos de gênero surgem como classificadores de práticas sexuais ora autorizadas ora proibidas, e são utilizados para relativizarem leis que entendem determinadas práticas como violentas. Aqui a figura do homem aparece como hiperssexualizada, e a figura da mulher de forma dicotômica, ora vulnerável ora sexualmente responsável.

Apesar disso, as identidades de gênero não são fixas. Para Butler ${ }^{15}$, mesmo que as expressões de gênero sejam produzidas e naturalizadas em torno ao masculino e o feminino, elas também são desconstruídas e transformadas, seu caráter plural permite rupturas dentro de um sistema naturalizado.

O acionamento discursivo da Lei Maria da Penha $^{29}$ e da Lei de Estupro de Vulnerável ${ }^{28}$ por parte dos adolescentes trouxe as seguintes questões: Os adolescentes estão mais cientes de seus direitos? De que maneira as informações sobre as leis chegaram? Como a (des)informação sobre os próprios direitos influenciam a agência dos conflitos?

A princípio, acreditamos que os jovens não estejam necessariamente mais conscientes de seus direitos, pois, discursivamente, as leis funcionavam como um agente de controle da sexualidade demarcado pelo gênero. As violências atreladas a essas leis foram demarcadas de forma polarizada, rapazes/agressores e moças/vítimas. Conforme Sarti ${ }^{30}$, observamos que as percepções sobre a violência dizem respeito ao que se convenciona como vítima mais do que pelo ato em si.

Quanto à análise sobre a percepção dos adolescentes acerca das violências vivenciadas, parte das narrativas que poderiam ser categorizadas, teoricamente, como violentas foram interpretadas como: acontecimentos "ruins", "chatos" e “desagradáveis". As situações identificadas pelos adolescentes de fato como ações violentas ou abusivas foram episódios com algum impacto negativo marcante.

Os rapazes apresentaram maior dificuldade em perceber a violência vivida, enquanto sujei- tos-alvos de agressões, e as moças pouco reconheceram a violência praticada por elas mesmas. Cada um possui inúmeras maneiras de perceber e conceber um evento, esses significados podem variar de acordo com as construções culturais e socioeconômicas do sujeito e, a partir do momento em que ganha um sentido, o evento vai sendo incorporado às relações ${ }^{18}$.

Quando questionados sobre o que significa violência e "relacionamento abusivo" no "ficar" e no namoro, a maioria dos interlocutores as definiram como categorias distintas. Os que correlacionaram violência às agressões físicas a interligaram a atos que geram danos físicos mais sérios e visíveis, exemplificando com casos de repercussão midiática, o sistema das "ações violentas graves”. Durante as entrevistas, as explicações dadas à violência levantam a hipótese de que a maior parte dos adolescentes que praticou e/ou viveu algum tipo de agressão física não o tenha citado por não as terem associado a casos "graves".

Já o termo "relacionamento abusivo" foi aludido às questões de ordem psicológica e coerções sexuais: "quando a pessoa quer tentar passar dos limites [...] Quer forçar uma coisa que sabe que não se sente bem, mas quer fazer aquilo porque ele gosta; A pessoa usar o seu sentimento, sabendo que você é apaixonada” (Lígia, 18 anos).

Os significados atribuídos ao "relacionamento abusivo" dizem respeito às ações cotidianas que geram mal-estar, mas são difíceis de serem identificadas como violentas, assim como no sistema da "sofrência". Essa percepção pode gerar o risco das agressões permanecerem no lugar apenas do incômodo e desagrado e de banalizaremse no dia a dia.

\section{As fronteiras entre o dito e o não dito: agência dos conflitos}

De acordo com Ortner ${ }^{18}$, as agências ocorrem como "formas de poder que as pessoas têm à sua disposição, de sua capacidade de agir em seu próprio nome, de influenciar outras pessoas e acontecimentos e de manter algum tipo de controle sobre suas próprias vidas"18(p.64). Desse modo, cada sujeito irá agir, reagir e resistir aos conflitos.

A agência não é um processo simplesmente individual e autônomo, pois o sujeito não controla completamente as teias sociais em que está inserido, assim, a agência se desenrola de forma interativa e negociada nas relações sociais. Quer dizer, a agência é atravessada, por um lado, pelas relações de solidariedade e, por outro, pelas relações de poder e de desigualdade. 
Quanto às agências realizadas pelos adolescentes em seus relacionamentos, o revide de agressões, os insultos e o acionamento de amigos e familiares para a intervenção nas situações de conflito foram as ações mais citadas. Contudo, quando questionados de forma direta sobre como resolviam os conflitos, a maioria respondeu que buscava o diálogo. Logo, é diferente o modo compreendido como ideal para resolução de conflitos e a gestão dos sentimentos e atitudes que emergem em um momento de tensão. Em meio às relações de poder e desigualdades, as emoções e as agências são complexas e contraditórias $^{18}$.

Os adolescentes apresentam resistência em solicitar ajuda, contudo os pares são os mais presentes e os mais acionados para aconselhamento e para ajudarem a resolver os problemas. Isto converge com a análise de Murta e Santos ${ }^{31}$, que aborda que conversar com os amigos traz mais conforto, pois vivenciam situações próximas nos relacionamentos.

Poucos citam a família como apoio, já que parte dos adolescentes disseram ter dificuldade de relação com os pais. $\mathrm{O}$ receio em conversar e pedir ajuda aos adultos era devido à falta de confiança e vergonha de se expor. De acordo com Njaine et. al. ${ }^{32}$, esta dificuldade retrata o modo como muitos jovens se consideram sozinhos no momento de lidar com este tipo de problemas resultando em uma ausência de orientações.

A busca por ajuda pode representar fragilidade, o que faz com que, principalmente, os meninos tendam a resolver os problemas sozinhos, como ilustrado a seguir: "Se ficar demonstrando muita fraqueza, vou acabar parecendo muito vítima e não sou vítima de nada. [...] vou acabar me ferrando, então prefiro ter mais postura, mostrar confiança" (Guilherme, 18 anos, negro).

Nesse sentido, Ortner ${ }^{18}$ assinala que a agência é construída social e culturalmente, com isso, também é atravessada pelo gênero, pelas diferenças e desigualdades. Para os meninos, assumir que vivenciam uma violência pode ser mais uma maneira de demonstrar fraqueza e colocar a masculinidade à prova, $o$ que sugere que possa ser um dos fatores para os rapazes não falarem ou minimizarem as violências vividas.

Levantamos a hipótese de que o receio do julgamento estabelece uma fronteira entre os adolescentes e suas redes de convivência, demarcando as situações que são passíveis de serem faladas e as que devem ser mantidas em sigilo. Por exemplo, há enredos que são socialmente aceitos, como o ciúme. Episódios passados e superados também são passíveis de serem verbalizados. Entretanto, situações atuais que podem ser consideradas "graves" e/ou que estão sujeitas a julgamentos, tendem a serem mantidas em sigilo.

Não solicitar ajuda também pode estar interligado à dificuldade de ver-se em uma relação com violência, há uma lacuna entre a identificação e a experiência. É mais difícil compreender situações mais abstratas e de microviolências, haja vista que as ações não concretizadas no corpo demoram a serem elaboradas como violentas.

A diferenciação existente para os adolescentes sobre o que é da ordem do "relacionamento abusivo" e da violência define em quais situações devem procurar apoio institucional, ocorrendo geralmente quando há violência física. Com isto, corre-se o risco de minimizar a gravidade e efeitos de outros tipos de violências na saúde mental, física e social dos sujeitos. Assim sendo, cuidados em saúde, e ações de prevenção à violência têm seu potencial limitado.

Ao tentarmos identificar a quem ou quais instituições eles recorreriam como apoio se, hipoteticamente, vivenciassem alguma violência; unanimemente indicaram a Delegacia de Polícia, porém mencionaram para as violências "sérias", como a seguir: "Sério para mim seria bater, forçar o ato e tal" (Carlos, 19 anos, pardo). Poucos apontaram como possibilidade a família, psicólogo e/ ou psiquiatra.

É relevante notar que os órgãos de garantia de direito e de promoção de cuidado não foram citados, como por exemplo, os equipamentos de saúde, da assistência social, escolares e os Conselhos Tutelares. É importante considerar a fragilidade das instituições no debate sobre violências e sexualidade, tornando o tema quase "invisível", e, consequentemente, distanciando estes locais como pontos de referência de cuidado e proteção.

\section{Considerações finais}

Há a necessidade de problematizar as formas de vivenciar as relações afetivo-sexuais que ultrapassam os tradicionais padrões de gênero. Reconhecer que as moças praticam violências não significa afirmar que a violência é simétrica, pois as hierarquias e desigualdades de gênero vulnerabilizam de formas diferentes as meninas e os meninos. Em suma, como é bem sabido, as moças e as mulheres têm maiores desvantagens sociais e tendem a ser alvo das violências mais graves, $\mathrm{e}$ com maior recorrência, quando comparado com o universo masculino. 
Não identificamos uma busca efetiva por parte dos adolescentes por seus direitos. De um lado, a falta de entendimento de quais são os espaços de proteção e garantia de direitos ou de seus funcionamentos e objetivos. Por outro lado, a frágil discussão jurídica quanto à proteção frente à violência no relacionamento afetivo-sexual vivenciada por adolescentes, tanto no Estatuto da Criança e do Adolescente ${ }^{10}$ quanto na Lei Maria da Penha ${ }^{29}$, que não contemplam esta questão de forma clara em seus artigos.

A pesquisa deixa algumas lacunas que precisam ser preenchidas em outro momento. $\mathrm{O}$ silenciamento a respeito do tema que contribui para a invisibilidade da violência no namoro e no "ficar" nas instituições e políticas públicas de garantia de direitos; a expansão de estudos sob a lente dos marcadores sociais da diferença; os sistemas das violências nas relações homoafetivas; os atravessamentos gerados pelas tecnologias digitais; as potencialidades das agências diante da violência e as mudanças nas formas de vivenciar o gênero e a sexualidade.

Diante dos desafios apresentados por Caridade e Machado ${ }^{5}$ nas pesquisas sobre violência no namoro, esta pesquisa nos permite apontar a aproximação dos sujeitos não inseridos em rede escolar como um desafio importante. No plano analítico, a definição de violência é um ponto ainda complexo que demanda atenção.

A partir dos movimentos sociais, do feminismo e do aumento da discussão sobre violência contra a mulher, termos como relacionamento abusivo e tóxico são usados como sinônimos de violência. É importante compreender se tal diversificação de sentidos influencia em algum grau na capacidade de reflexão e rompimento do ciclo da violência entre os adolescentes ou se, pelo contrário, dificulta a percepção e identificação das violências vivenciadas.

Por fim, a despeito da escola reproduzir certo controle sobre a sexualidade e imposição de moralidades acreditamos na potência transformadora da educação. Entendemos a escola como um agente fundamental para o debate da sexualidade, do gênero e da violência, bem como um local para instrumentalizá-los a perceberem as possíveis violências vividas e praticadas em seus relacionamentos, e as instituições às quais podem recorrer.

Portanto, apostamos na potência da informação e do diálogo com os adolescentes sobre questões pertinentes às suas trajetórias afetivosexuais, o que pode contribuir para o fortalecimento das agências frente às violências e o reconhecimento dos adolescentes como sujeitos de direitos.

\section{Colaboradores}

RS Carvalhaes coletou os dados, idealizou o artigo e participou de todas as fases de sua elaboração. CM Mora Cárdenas participou de todas as fases de elaboração do artigo.

\section{Referências}

1. Krug EG, Dahlberg LL, Mercy JA, Zwi AB, Lozano R. Relatório Mundial sobre Violência e Saúde. Genebra: OMS; 2002.

2. Nascimento FS. Namoro e Violência: um estudo sobre amor, namoro e violência para jovens de grupos populares e camadas médias [dissertação]. Recife: Universidade Federal de Pernambuco; 2009.

3. Minayo MCS, Assis SG, Njaine K, organizadores. Amor e violência: um paradoxo das relações de namoro $e$ do 'ficar' entre jovens brasileiros. Rio de Janeiro: Ed. Fiocruz; 2011.

4. Barreira AK, Lima MLC, Avanci JQ. Coocorrência de violência física e psicológica entre adolescentes namorados do Recife, Brasil: prevalência e fatores associados. Cien Saude Colet 2013; 18(1):233-243. 
5. Caridade S, Machado C. Violência na intimidade juvenil: Da vitimação à perpetração. Ana Psicol 2006; 24(4):485-493.

6. Castro R, Casique I. Violencia em el noviazgo entre los jóvenes mexicanos. Cuernavaca: UNAM, CRIM; 2010.

7. Machado C, Antunes J. Violência nas relações íntimas ocasionais de uma amostra estudantil. Ana Psicol 2012; XXX(1-2):93-107.

8. Oliveira QBM, Assis SG, Njaine K, Oliveira RVC. Violências nas Relações Afetivo-Sexuais. In: Minayo MCS, Assis SG, Njaine K, organizadores. Amor e violência: um paradoxo das relações de namoro e do 'ficar' entre jovens brasileiros. Rio de Janeiro: Ed. Fiocruz; 2011.

9. Lenoir R. Objeto sociológico e problema social. In: Champagne P, Lenoir R, Merllié D, Pinto L. Iniciação à Prática sociológica. Petrópolis: Vozes; 1996. p. 59-106.

10. Brasil. Lei no 8.069, de 13 de julho de 1990. Dispõe sobre o Estatuto da Criança e do Adolescente e dá outras providências. Diário Oficial da União 1990, 16 jul.

11. Brasil. Lei $n^{\circ} 12.852$, de 5 de agosto de 2013. Institui o Estatuto da Juventude e dispõe sobre os direitos dos jovens, os princípios e diretrizes das políticas públicas de juventude e o Sistema Nacional de Juventude. Diário Oficial da União 2013; 6 ago.

12. Víctora CG, Knauth DR, Hanssen MNA. Pesquisa qualitativa em saúde: uma introdução ao tema. Porto Alegre: Tomo Editorial: 2000.

13. Brasil. Resolução no 466, de 12 de dezembro de 2012. Conselho Nacional de Saúde. Diário Oficial da União 2013; 13 de jun.

14. Sousa FKM. Narrativas sobre relacionamentos abusivos e mudança de sensibilidades do que é violência. In: Seminário FESPSP, Incertezas do Trabalho. São Paulo; 2017.

15. Butler J. Problemas de gênero: feminismo e subversão da identidade. Rio de Janeiro: Civilização Brasileira; 2016.

16. Gagnon JH. Uma interpretação do desejo: ensaios sobre o estudo da sexualidade. Rio de Janeiro: Garamond; 2006.

17. Gregori MF. Cenas e queixas: um estudo sobre mulheres, relações violentas e a prática feminista. Rio de Janeiro: Paz e Terra; 1993.

18. Ortner SB. Poder e projetos: uma reflexão sobre a agência. In: Grossi MP, Eckert C, Fry PH, organizadores. Conferências e diálogos: saberes e práticas antropológicas: 25a Reunião de Antropologia, Goiânia - 2006. Blumenau: Nova Letra; 2007. p. 45-80.

19. Bozon M, Heilborn ML. Iniciação à sexualidade: Modos de socialização, interações de gênero e trajetórias individuais. In: Heilborn ML, Aquino EML, Bozon M, Knauth DR, organizadores. O aprendizado da sexualidade: Reprodução e trajetórias sociais de jovens brasileiros. Rio de Janeiro: Garamond e Fiocruz; 2006.

20. Heilborn ML, Aquino EML, Bozon M, Knauth DR, organizadores. O aprendizado da sexualidade: Reprodução e trajetórias sociais de jovens brasileiros. Rio de Janeiro: Garamond e Fiocruz; 2006.

21. Parreiras C. Altporn, corpos, categorias, espaços e redes: um estudo etnográfico sobre pornografia online [tese].
Campinas: Universidade Estadual de Campinas; 2015.

22. Petrosillo IR. Esse nu tem endereço: o caráter humilhante da nudez e da sexualidade feminina em duas escolas públicas [dissertação]. Niterói: Universidade Federal Fluminense; 2016.

23. Jones D. "Cidade Pequena, Inferno Grande": Fofoca e Controle Social da Sexualidade entre adolescentes da cidade de Trelew (Argentina). In: Heilborn ML, Aquino EM, Barbosa RM, Bastos FI, Rohden F. Sexualidade, Reprodução e Saúde. Rio de Janeiro: Ed. FGV; 2009.

24. Goffman E. Estigma - notas sobre a manipulação da identidade deteriorada. Rio de Janeiro: LTC; 1988.

25. Louro GL. Pedagogias da sexualidade. In: Louro, GL, organizador. O Corpo Educado: Pedagogias da sexualidade. Belo Horizonte: Ed. Autentica; 2000.

26. Rezende CB, Coelho MC. Antropologia das emoções. Rio de Janeiro: Ed. FGV; 2010.

27. Flach RMD, Deslandes SF. Abuso digital nos relacionamentos afetivo-sexuais: uma análise bibliográfica. Cad Saude Publica 2017; 33(7):e00138516.

28. Brasil. Lei $\mathrm{n}^{\circ}$ 12.015, de 07 de agosto de 2009. Dispõe sobre os crimes hediondos, nos termos do inciso XLIII do art. $5^{\circ}$ da Constituição Federal e revoga a Lei $\mathrm{n}^{\circ} 2.252$, de $1^{\circ}$ de julho de 1954, que trata de corrupção de menores. Diário Oficial da União 2009; 10 ago.

29. Brasil. Lei no 11.340 , de 07 de agosto de 2006. Dispõe sobre a criação dos Juizados de Violência Doméstica e Familiar contra a Mulher; altera o Código de Processo Penal, o Código Penal e a Lei de Execução Penal; e dá outras providências. Diário Oficial da União 2006; 08 ago.

30. Sarti CA. Corpo, violência e saúde: a produção da vítima. Sex Salud Soc 2009; 1:89-103.

31. Murta SG, Santos KB. Influência dos Pares e Educação por Pares na Prevenção à Violência no Namoro. Psicol Cien Prof 2016; 36(4):787-800.

32. Njaine K, Oliveira QBM, Ribeiro FML, Minayo MCS, Bodstein R. Prevenção da Violência nas Relações Afetivo-Sexuais. In: Minayo MCS, Assis SG, Njaine K. Amor e violência: um paradoxo das relações de namoro $e$ do 'ficar' entre jovens brasileiros. Rio de Janeiro: Ed. Fiocruz; 2011.

Artigo apresentado em 20/04/2020

Aprovado em 22/04/2021

Versão final apresentada em 24/04/2021

Editores-chefes: Romeu Gomes, Antônio Augusto Moura da Silva 